\title{
Elbow Injury Prevention in Youth Dominican Baseball Players: A Training Intervention Pilot Study
}

Chelsey Erbaugh Franz

Bellarmine University, Louisville, cfranz@bellarmine.edu

Dawn Hall-Bibb

Bellarmine University, Louisville, dhallbibb@bellarmine.edu

Myra Stockdale

Bellarmine University, Louisville, mstockdale@bellarmine.edu

Aliya Thompson

Bellarmine University, Louisville, athompson14@bellarmine.edu

Bailey Biggs

Bellarmine University, Louisville, bbiggs@kort.com

Follow this and additional works at: https://nsuworks.nova.edu/ijahsp

Part of the Community Health Commons, Community Health and Preventive Medicine Commons, Interprofessional Education Commons, Other Analytical, Diagnostic and Therapeutic Techniques and Equipment Commons, Other Rehabilitation and Therapy Commons, Sports Sciences Commons, and the Therapeutics Commons

\section{Recommended Citation}

Franz CE, Hall-Bibb D, Stockdale M, Thompson A, Biggs B. Elbow Injury Prevention in Youth Dominican Baseball Players: A Training Intervention Pilot Study. The Internet Journal of Allied Health Sciences and Practice. 2019 Jan 01;17(3), Article 6.

This Manuscript is brought to you for free and open access by the College of Health Care Sciences at NSUWorks. It has been accepted for inclusion in Internet Journal of Allied Health Sciences and Practice by an authorized editor of NSUWorks. For more information, please contact nsuworks@nova.edu. 


\title{
Elbow Injury Prevention in Youth Dominican Baseball Players: A Training Intervention Pilot Study
}

\begin{abstract}
Background: Research suggests deficits in shoulder and elbow strength and flexibility may explain the role of elbow injuries in overhead athletes, specifically ulnar collateral ligament (UCL) injury in baseball players. Significant damage to this ligament typically requires operative care for continued activity in the sport. Several studies have demonstrated the success of rehabilitation programs post-surgery; however, few studies have examined the role of UCL injury prevention programs. A recognized upper extremity (UE) injury prevention method is the Thrower's Ten Program. This program may create elbow stability when pitching and throwing, theoretically reducing the risk of UCL injury. Purpose: The purpose of this study is to explore the feasibility of teaching this program to youth baseball coaches in a Spanish-speaking, developing country. Design: This is a pilot study carried out at the Youth Baseball Academy in Santiago, Dominican Republic. Participants included youth male baseball players $(\mathrm{N}=24)$, aged 14 to 18 years, who completed a health history survey. Dominican male coaches $(\mathrm{N}=5)$, aged 21 to 35 years, averaging seven years of coaching, were taught the Thrower's Ten program. Two days post training and one-year post training, the coaches were assessed on their ability to properly demonstrate the exercises. The main outcome measures were a baseline of UE injuries in a baseball academy; proper demonstration of exercises as tracked on a Thrower's Ten Program checklist; and implementation of the program. Results: Nearly $80 \%$ (19 of 24) of the youth baseball players recorded a current or previous UE injury. All coaches achieved a $100 \%$ (21 of 21) accuracy rate two days post training and the pitching coached achieved an $85 \%$ (18 of 21 ) one year later. The pitching coaches utilized the program three times per week. Conclusions: Findings suggest UE injury prevention programs are needed and can be successfully integrated into a Dominican youth baseball academy.
\end{abstract}

\section{Author Bio(s)}

Chelsey Erbaugh Franz, PhD, ATC, is a Clinical Education Coordinator in the Master of Science in Athletic Training Program and Assistant Professor in the College of Health Professions, School of Movement and Rehabilitation Sciences at Bellarmine University in Louisville, KY. She is also a licensed athletic trainer in the state of Kentucky.

Dawn Hall-Bibb, PT, PhD, MPT, is an Associate Professor in the College of Health Professions, School of Movement and Rehabilitation Sciences at Bellarmine University in Louisville, KY. She is also a licensed physical therapist in the state of Kentucky.

Myra Stockdale, ATC, DHSc, is a Program Director in the Master of Science in Athletic Training Program and Assistant Professor in the College of Health Professions, School of Movement and Rehabilitation Sciences at Bellarmine University in Louisville, KY. She is also a licensed athletic trainer in the state of Kentucky and Indiana.

Aliya Thompson is a graduate student in the Doctor of Physical Therapy Program in the College of Health Professions, Movement and Rehabilitation Sciences at Bellarmine University in Louisville, KY.

Bailey Biggs in an exercise and sport science graduate in the College of Health Professions, Movement and Rehabilitation Sciences at Bellarmine University in Louisville, KY.

\section{Acknowledgements}

Acknowledgements: Go Sports supported this study through access to their Dominican coaches and athletes in their baseball academy. This study was approved by Bellarmine University's Institutional Review Board, study \#563.

This manuscript is available in Internet Journal of Allied Health Sciences and Practice: https://nsuworks.nova.edu/ijahsp/vol17/iss3/6 


\title{
TIUAHSP \\ The Internet Journal of Allied Health Sciences and Practice \\ Dedicated to allied health professional practice and education
}

Vol. 17 No. 3 ISSN 1540-580X

\section{Elbow Injury Prevention in Youth Dominican Baseball Players: A Training Intervention Pilot Study}

\author{
Chelsey Erbaugh Franz \\ Dawn Hall-Bibb \\ Myra Stockdale \\ Aliya Thompson \\ Bailey Biggs \\ Bellamarmine University \\ United States
}

\begin{abstract}
Background: Research suggests deficits in shoulder and elbow strength and flexibility may explain the role of elbow injuries in overhead athletes, specifically ulnar collateral ligament (UCL) injury in baseball players. Significant damage to this ligament typically requires operative care for continued activity in the sport. Several studies have demonstrated the success of rehabilitation programs post-surgery; however, few studies have examined the role of UCL injury prevention programs. A recognized upper extremity (UE) injury prevention method is the Thrower's Ten Program. This program may create elbow stability when pitching and throwing, theoretically reducing the risk of UCL injury. Purpose: The purpose of this study is to explore the feasibility of teaching this program to youth baseball coaches in a Spanish-speaking, developing country. Design: This is a pilot study carried out at the Youth Baseball Academy in Santiago, Dominican Republic. Participants included youth male baseball players (N=24), aged 14 to 18 years, who completed a health history survey. Dominican male coaches $(\mathrm{N}=5)$, aged 21 to 35 years, averaging seven years of coaching, were taught the Thrower's Ten program. Two days post training and one-year post training, the coaches were assessed on their ability to properly demonstrate the exercises. The main outcome measures were a baseline of UE injuries in a baseball academy; proper demonstration of exercises as tracked on a Thrower's Ten Program checklist; and implementation of the program. Results: Nearly $80 \%$ (19 of 24) of the youth baseball players recorded a current or previous UE injury. All coaches achieved a $100 \%$ (21 of 21) accuracy rate two days post training and the pitching coached achieved an $85 \%$ (18 of 21) one year later. The pitching coaches utilized the program three times per week. Conclusions: Findings suggest UE injury prevention programs are needed and can be successfully integrated into a Dominican youth baseball academy.
\end{abstract}

Keywords: injury prevention, elbow, upper extremity, strength, flexibility

( The Internet Journal of Allied Health Sciences and Practice, 2019 


\section{INTRODUCTION}

In the Dominican Republic (DR), baseball is king. Seen as the best option to escape the poverty commonly found in a developing country, parents opt to bypass traditional schooling, sending their sons to one of the many baseball academies on the island. ${ }^{1-4}$ Every US major league baseball team has a baseball academy in the DR. Youth are recruited from rural communities and big cities alike to take part in the academies. With the goal to sign a major league contract at the age of 16 , emphasis is placed on performing at a high level; little regard is given to injury prevention. ${ }^{1-4}$ Athletic trainers play a key role in the treatment and prevention of athletic injuries. The profession was created, in part, with the intent to provide access to high quality health care for those lacking resources. ${ }^{5}$ In addition, new curriculum standards require athletic training students to gain experience with underserved populations, including those facing barriers to good health as a result of social determinants and socio-economic status. ${ }^{6}$ Thus, athletic trainers are well-suited to address upper extremity (UE) injury prevention within these baseball academies.5,6

Non-contact upper extremity injuries are common in baseball. In the United States, baseball is the fourth most common sport played among high school boys, with nearly 500,000 participants in the 2016-2017 academic year. ${ }^{7}$ Roughly one-fourth of these players will pitch. ${ }^{8}$ Research suggests deficits in shoulder and elbow strength and flexibility may explain the role of elbow injuries in overhead athletes, specifically baseball players. ${ }^{9-13}$ Ulnar collateral ligament injuries to the elbow range from slight tissue stretching to full ligament rupture. Partial tears and full ruptures of this ligament typically require reconstructive care for continued activity in sport. Since the original surgery in 1974 by Dr. Frank Jobe, surgeons have modified the procedure, seeking improved return to play outcomes. Reconstruction rates remained relatively stable until 1998, when researchers first noted a small peak in surgeries. However, in the last decade, reconstruction rates have increased at a significant rate..$^{14}$ One study found that from 20032014 , reconstructions rates jumped $343 \%$. The number of UCL reconstructions was highest in the $15-19$ year old male athlete and were predicted to increase by 2025 from 6.3 per 100,000 to 14.6 per 100,000.15 With the reconstruction surgery, athletes return to play at a high rate. Studies found as high as $90 \%$ of athletes returned to pre-injury level following UCL reconstruction. ${ }^{16-18}$ However, surgery is invasive and can be unrealistic in developing countries; thus, an effort to integrate preventative programs are needed. The Thrower's Ten Program is an exercise intervention that strengthens and increases flexibility in the muscles surrounding the shoulder and elbow joints. ${ }^{19}$ The purpose of this study is to assess the feasibility of teaching the Thrower's Ten Program (an upper extremity injury prevention program) to youth baseball coaches at a baseball academy in a Spanish-speaking, developing country.

\section{METHODS}

Researchers utilized a case report design to assess the feasibility of teaching the Thrower's Ten Program to youth baseball coaches in a Spanish-speaking, developing country. Five Dominican youth baseball coaches from Go Ministries Sports (the full coaching staff for their baseball academy) in Santiago, DR, participated in the pilot study. Coaches were recruited based on their job descriptions and excluded from the study if they were unavailable to participate in the training session or follow up evaluation. Researchers utilized a translator to read an informed consent to the coaches, and provided a Spanish-copy of the form to the coaches. In addition, researchers gathered basic demographics on the coaches.

Researchers assessed understanding and application of the Thrower's Ten Program with a case report design. Initially, with the assistance of a translator, researchers gave the coaches a description of the intervention and its importance in maintaining longterm upper extremity health of their athletes. Following this, the researchers trained the coaches on the proper technique and application of the Throwers Ten program. A laminated copy of the complete program (in both Spanish and English) was posted on the batting cages at the Go Sports baseball training facility, ensuring the coaches could easily follow the program. Additionally, researchers purchased tubing to leave with the team, so all exercises could be completed. The researchers also offered alternatives to the tubing (baseballs, bats), in the event the tubing was no longer available.

Two days after the training, the researchers met with each coach individually, utilizing a checklist, to ensure the coaches understood the exercises and were able to properly demonstrate how to perform the exercise. One year post-training, researchers assessed the pitching coach's ability to instruct his athletes on the Thrower's Ten Program and ascertained the frequency with which the program was utilized among the players. Finally, utilizing a health-history questionnaire, researchers assessed the prevalence of elbow and shoulder injuries among Go Sports baseball athletes. Bellarmine University's Institutional Review Board approved all study methodology (study \# 563). 


\section{RESULTS}

Posttest assessment showed the Dominican male coaches, aged 21 to 35 years, averaging seven years of coaching, understood and were able to properly demonstrate the Thrower's Ten Program for youth baseball players in the Go Sports program. Utilizing the checklist, coaches achieved a $100 \%$ (21 of 21 ) accuracy rate.

One year post training, researchers met with the Go Sports pitching coach, age 35, with 13 years of coaching. Follow up assessment showed he was able to properly demonstrate the Thrower's Ten Program for his youth baseball players in the Go Sports program. Utilizing the checklist, he achieved an $85 \%$ (18 of 21) accuracy rate. In addition, he and the athletes stated they used the program three times a week with his pitchers. The laminated Thrower's Ten Program remained on the batting cage; the researchers replaced damage or missing tubing.

Health history questionnaires revealed nearly $80 \%$ of Go Sports youth male baseball players (age 14-18) had an UE injury at some point during their baseball career. Of the 24 athletes surveyed, 19 identified a previous injury to their shoulder, elbow, forearm, wrist or hand.

\section{DISCUSSION}

Injuries in youth sports is a growing concern with the increased prevalence of play. In baseball specifically, the drastic increase in UCL reconstructions is alarming. For Dominican athletes, youth baseball academies are a way of life. Risk to players in these settings are increased, with a focus on the health and well-being of the athlete secondary to signing major league contracts. ${ }^{1-4}$ Different from the MLB academies, Go Sports has an emphasis on player development, requiring their athletes to attend school, learn English, and work towards perfecting a trade, with the goal of reducing poverty and improving long-term health and wellness of their athletes, regardless of their baseball prospects. ${ }^{4}$

The success of this pilot study was encouraging for several reasons. First, working with Go Sports proved beneficial to the athletes and researchers alike, a primary goal of community-based research. ${ }^{20,21}$ Go Sports coaches, and thus their athletes, were receptive to the Thrower's Ten Program, enhancing the chances of long-term use of the program. Likely this was because of the strength of the leadership within Go Sports. Coaches appeared to trust the administrators, who recommended use of the program. Go Sports administrators are Americans, former college athletes, who requested injury prevention programs for their academy. With their approval, researchers were able to get "buy-in" from the coaches and athletes. In addition, within a few months of adopting the program, the Go Sports pitching coach used the program to rehabilitate what he understood to be a full UCL tear on one of his pitchers. He believed the program was the main reason for his athlete's full recovery. Though highly unlikely, his belief ensured he used the program consistently and long-term with his players.

Second, this pilot study created discussion for future injury prevention programs for other Go Sports academies. These include boys and girls basketball, girls soccer, and girls volleyball. Follow-up injury prevention programs, and subsequent research projects, are underway for knee injuries in female youth Dominican athletes as well as continued work with elbow injuries in youth baseball players. ${ }^{4}$

Third, this study was part of a faculty-lead immersion experience for students from a US university. The visit to the DR gave faculty and students the opportunity to collect data first-hand on athletes in developing countries and work alongside community members, seeking a common goal. This addressed curriculum requirements for the university students and met the goal of high-impact educational practices, providing a rich experience for students and faculty alike. ${ }^{20,21}$

Finally, this study was inter-professional among allied health professionals, athletic training and physical therapy faculty members. Breaking down academic and professional silos enhances understanding of one another's' skill set, encouraging collaboration outside of the research realm, leading to better student learning and, more importantly, better patient outcomes. ${ }^{20-23}$

\section{Limitations}

This study was not, however, without its limitations. First, this pilot study addressed injury prevention through a strengthening and flexibility program. Empirical evidence supports the theory that UCL tears occur as a result of a multitude of factors. These include pitch count, pitch speed, rest between days of pitching, repertoire of pitches, stature of the athlete, fatigue of pitcher, position of player (catcher), and horizontal release location of pitch. ${ }^{9,13,24-26}$ In 2012, Fleisig and Andrews conducted a search of available data regarding elbow injuries in youth baseball players. Their findings suggest that while upper extremity strength and flexibility is a contributing factor, non-contact injuries in the dominant arm of baseball players were primarily the result of repetitive pitching. 
The authors reported that $5 \%$ of youth baseball pitchers suffer an elbow or shoulder injury serious enough to dictate surgery or career ending decisions. These injuries occurred within a 10-year period of playing youth baseball. A 2016 study by McHugh et al demonstrated the effect of high pitch volume on the supraspinatus musculature. Using pitchers from 2 high schools for 4 consecutive seasons, for a total of 95 player-seasons, the authors found pitchers with an increased pitch volume (defined as greater than 400 pitches thrown in a season) had significantly weaker supraspinatus strength in-season and diminished strength gain from one season to the next, potentially pre-disposing an athlete to a UCL tear in future seasons. These findings were supported by several other reviews of the literature and research studies, all pointing to repetitive pitching as the primary culprit of UCL injury. 9,15,19,25,27 Moving forward, a study aimed at working with the Dominican coaches on pitch count and days of rest is warranted.

Second, this program ideally would be utilized with all overhead athletes in Go Sports baseball academy, not just pitchers, as UCL tears occur in position players as well, specifically catchers. However, Go Sports coaches turned the program over to the pitching coach, who chose to use the program solely with the pitchers, thus limiting the effectiveness. Further discussions regarding the need to include, at a minimum, the catchers in the preventative training is warranted.

Third, much of the evidence regarding UCL tears is on adult athletes. Empirical evidence regarding youth athletes and the effect of pitching on the elbow is lacking. Specifically, research on baseball academies in developing countries is sparse. This gap in the literature indicates a need and opportunity for further exploration.

\section{CONCLUSIONS}

Our findings indicate Dominican youth baseball coaches with Go Sports can adequately implement the Thrower's Ten Program for long-term upper-extremity injury prevention among their baseball academy athletes. Health history questionnaires indicated a need to address UE injuries in these athletes; adding the Thrower's Ten Program to training sessions may be beneficial to the long-term UE health of all their overhead athletes.

\section{Acknowledgments}

The researchers would like to thank Go Ministry, specifically their sports outreach, for collaboration and support of this pilot study. In Dominican sports, little emphasis is placed on injury prevention. Bringing an injury prevention program to an academy unfamiliar with the importance of training and prevention exercises posed some issues regarding program adoption. Additionally, the DR is a culture of machismo, where males demonstrate aggressive masculine pride, giving little respect to females. On this pilot study, all researchers were female. The strength of Go Sports leadership proved instrumental in the adoption of this program by the Go Sports coaches.

\section{References}

1. Hanlon R. School's Out Forever; The Applicability of International Human Rights Law to Major League Baseball Academies in The Dominican Republic. In: J.D. University of the Pacific MSoL, ed., 2013.

2. Klein A. Dominican Baseball: New Pride, Old Prejudice. Philadelphia, PA: Temple University Press, 2014.

3. Wasch A. Children Left Behind: The Effect of Major League Baseball on Education in the Dominican Republic. In: Law FIUCo, ed., 2009.

4. Bradley K, Pardin W, Martinez J. Go Sports, 2016.

5. National Athletic Trainers' Association. NATA Quick Facts. Secondary NATA Quick Facts 2018. https://www.nata.org/nata-quick-facts

6. Commission on Accreditation of Athletic Training. Commission on Accreditation of Athletic Training. Secondary Commission on Accreditation of Athletic Training 2018. https://caate.net

7. National Federation of State High School Associations. Participation Statistics. Secondary Participation Statistics 2017. http://www.nfhs.org/ParticipationStatistics/PDF/2016-17_Participation Survey Results.pdf

8. Lyman S, Fleisig GS. Baseball Injuries. Medicine and Sport Science 2005;49:9-30

9. McHugh M, Tyler T, Mullaney M, Mirabella M, Nicholas S. The Effect of High Pitch Volume on Musculoskeletal Adaptations in High School Baselball Pitchers. American Orthopaedic Society for Sports Medicine 2016;44(9):2246-54 doi: https://doi.org/10.1177/0363546516650183[published Online First: Epub Date

10. Reinold MM, Wilk KE, Macrina LC, et al. Changes in Shoulder and Elbow Passive Range of Motion after Pitching in Professional Baseball Players. The American Journal of Sports Medicine 2008;36(3):523-27 doi: 10.1177/0363546507308935[published Online First: Epub]. 
11. Wilk KE, Macrina LC, Fleisig GS, et al. Deficits in Glenohumeral Passive Range of Motion Increase Risk of Elbow Injury in Professional Baseball Pitchers: A Prospective Study. The American Journal of Sports Medicine 2014;42(9):2075-81 doi: 10.1177/0363546514538391[published Online First: Epub]

12. Fronek J, Yang J, Osbahr DC, et al. Shoulder functional performance status of Minor League professional baseball pitchers. Journal of Shoulder and Elbow Surgery 2015;24(1):17-23 doi: https://doi.org/10.1016/i.jse.2014.04.019[published Online First: Epub].

13. Fleisig GS, Andrews JR. Prevention of Elbow Injuries in Youth Baseball Players. Sports Health 2012;4(5):419-24 doi: 10.1177/1941738112454828[published Online First: Epub].

14. Camp C, Conte S, D'Angelo J, Fealy S. Epidemiology of Ulnar Collateral Ligament Reconstruction in Major and Minor League Baseball Pitchers: Comprehensive Report on 1,313 Cases. Orthopaedic Journal of Sports Medicine 2017;5(7) doi: 10.1177/2325967117S00369[published Online First: Epub].

15. Mahure S, Mollon B, Shamah S, Kwon Y, Rokito A. Disproportionate Trends in Ulnar Collateral Ligament Reconstruction: projections through 2025 and a literature review. Journal of Shoulder and Elbow Surgery 2016;25(6):1005-21

16. Saper M, Shung J, Pearce S, Bompadre V, Andrews JR. Outcomes and Return to Sport After Ulnar Lateral Collateral Ligament Reconstruction in Adolescent Baseball Players. Orthopaedic Journal of Sports Medicine 2018;6(4) doi: 10.1177/2325967118769328[published Online First: Epub].

17. Jiang JJ, Leland JM. Analysis of Pitching Velocity in Major League Baseball Players Before and After Ulnar Collateral Ligament Reconstruction. The American Journal of Sports Medicine 2014;42(4):880-85 doi: 10.1177/0363546513519072[published Online First: Epub]

18. Osbahr DC, Cain EL, Raines BT, Fortenbaugh D, Dugas JR, Andrews JR. Long-term Outcomes After Ulnar Collateral Ligament Reconstruction in Competitive Baseball Players: Minimum 10-Year Follow-up. The American Journal of Sports Medicine 2014;42(6):1333-42 doi: 10.1177/0363546514528870[published Online First: Epub]

19. Redler L, Degen R, McDonald L, Altchek D, Dines J. Elbow Ulnar Lateral Collateral Ligament Injuries: Can we improve our outcomes? World Journal of Orthopedics 2016;7(4):229-43 doi: 10.5312/wjo.v7.i4.229[published Online First: Epub].

20. Cuff P. Building Health Workfoce Capacity Through Community-Based Health Professional Education: Workshop Summary: National Academy of Sciences, 2015.

21. Kuh G. High-Impact Educational Practices; What they are, Who has access to them, and Why they matter. Association of American Colleges and Universitites, 2008.

22. Outcomes CoMtlolEoCPaP, Health BoG, Medicine In. Measuring the Impact of Interprofessional Education on Collaborative Practice and Patient Outcomes: National Academy of Sciences, 2015.

23. Greiner A. Health Professions Education: A Bridge to Quality: National Academies of Science, 2003.

24. Whiteside D, Martini D, Lepley A, Zemicke R, Goulet G. Predictors of Ulnar Collateral Ligament Restruction in Major League Baseball Pitchers. The American Journal of Sports Medicine 2016;44(9):2202-09 doi: https://doi.org/10.1177/0363546516643812 [published Online First: Epub].

25. Yang J, Mann BJ, Guettler JH, et al. Risk-Prone Pitching Activities and Injuries in Youth Baseball: Findings From a National Sample. The American Journal of Sports Medicine 2014;42(6):1456-63 doi: 10.1177/0363546514524699[published Online First: Epub].

26. Lyman S, Fleisig GS, Andrews JR, Osinski ED. Effect of Pitch Type, Pitch Count, and Pitching Mechanics on Risk of Elbow and Shoulder Pain in Youth Baseball Pitchers. The American Journal of Sports Medicine 2002;30(4):463-68 doi: 10.1177/03635465020300040201[published Online First: Epub]

27. Olsen SJ, Fleisig GS, Dun S, Loftice J, Andrews JR. Risk Factors for Shoulder and Elbow Injuries in Adolescent Baseball Pitchers. The American Journal of Sports Medicine 2006;34(6):905-12 doi: 10.1177/0363546505284188[published Online First: Epub]. 